\title{
José Antonio Encinas y la reforma universitaria de Lima en 1931
}

Recibido: 05.12.2018

Aprobado: 17.06.2019

Néstor Jorge Machaca Arque

Universidad Nacional Mayor de San Marcos nestoruna@yahoo.es

\begin{abstract}
RESUMEN
La investigación tiene el propósito de destacar el protagonismo de José Antonio Encinas, uno de los principales pedagogos del Perú en el siglo xx, quien ejerció una notable influencia en la educación peruana. Este estudio se centra entre los años 1931 y 1932. Durante esta época en la que se produjeron acontecimientos que convulsionaron la sociedad peruana, el rector Encinas implementó la Reforma Universitaria de 1931. La misma que quedaría trunca en 1932 cuando la Universidad Nacional Mayor de San Marcos fue clausurada.
\end{abstract}

Palabras Clave: Encinas, reforma universitaria, San Marcos.

\section{Jose Antonio Encinas and the University Reform of Lima in 1931}

\begin{abstract}
The research is intended to highlight the leading role of José Antonio Encinas, one of the main educators of Peru in the 20th century, who exerted a remarkable influence on Peruvian education. This study focuses between the years 1931 and 1932 . During this period in which events occurred that convulcionaron the Peruvian society, Rector Encinas implemented the University reform of 1931. The same that would be truncated in 1932 when the Universidad Nacional Mayor de San Marcos was closed.
\end{abstract}

KeYwords: Encinas, university reform, San Marcos.

1 Los contenidos del artículo derivan de la tesis José Antonio Encinas y la educación indígena de los aimaras y quechuas: Puno 1900-1932 presentada para optar el grado académico de Doctor en Historia en la Univesidad Nacional Mayor de San Marcos, Lima, Perú. 


\section{Introducción}

J osé Antonio Encinas es una de las figuras más importantes de la actividad pedagógica en el Perú del siglo $\mathrm{xx}$, su obra ha recibido una larga y merecida atención desde la vertiente pedagógica que ha propiciado el debate educativo en la práctica docente durante las primeras tres décadas del siglo Xx en el Perú; por ello, este estudio se enmarca en el abordaje de la reforma universitaria que se produjo en la Universidad de San Marcos en 1931, la misma que fue conducida por Encinas en su condición de rector.

Encinas con su presencia en el escenario del debate había significado fuente permanente de sabiduría para las promociones de estudiantes, prestos a escuchar sus conferencias y clases, a quienes entregó generosamente su erudición pedagógica durante varias generaciones para alimentarlas espiritualmente bajo el filtro de la razón que era su verbo permanente, ya que tempranamente se había embarcado en el terreno educativo en el que había encontrado la satisfacción de desempeñarse plenamente.

Este estudio se justifica porque Encinas es una de las figuras más importantes de la pedagogía peruana del siglo $\mathrm{xx}$, reviste su peculiaridad ya que en este trabajo se vertebra un breve corpus teórico para comprender a Encinas como el promotor de un paradigma educativo para la educación latinoamericana y nacional a partir de una explicación histórica.

\section{El problema de investigación}

En esta investigación se pretendió responder a la siguiente interrogante:

¿Cuáles fueron las innovaciones implementadas por José Antonio Encinas en su condición de Rector de la Universidad Nacional Mayor de San Marcos que lideró la reforma universitaria hacia 1931 en la que introdujo una nueva educación universitaria?

Dentro de esa misma línea, como hipótesis se postula que José Antonio Encinas, Rector de la Universidad Nacional Mayor de San Marcos, lideró una implementación académica innovadora para su modernización en concordancia con las ideas de la reforma universitaria, en la que introdujo un nuevo modelo de educación universitaria.

\section{Metodología y perspectiva teórica}

La metodología asumida se enmarca dentro de la investigación cualitativa, ya que utiliza aspectos que no pueden cuantificarse, porque intrínsecamente tienen su propia significación, por lo que es pertinente utilizar criterios que conviene resaltar para su mejor entendimiento; así como se trata en lo posible de mantener la fidelidad de la información recogida, para reconstruir las condiciones que posibilitaron la estructuración de la máxima autoridad universitaria e intelectual en que se había consagrado Encinas.

$\mathrm{Al}$ respecto, Roger Chartier sobre historia intelectual, señala que la

Única definición aceptable en la actualidad de la historia intelectual o cultural parece ser la que da C. Schorske (a quien cita), el historiador busca situar e interpretar el artefacto temporariamente en un campo donde se cruza dos líneas. Una es vertical, o diacrónica, por la cual establece la relación de un texto o un sistema de pensamiento con una expresión previa de la misma rama de actividad cultural (pintura, política, etc.). La otra es horizontal o sincrónica; por medio de esta establece la relación del contenido del objeto intelectual con lo que parece en otras ramas o aspectos de una cultura al mismo tiempo (Chartier 2005: 41).

En esa perpectiva, la investigación es descriptiva porque aspira a decir cómo fueron los hechos, y explicativa, porque ya reconocidos los hechos entonces se requiere saber por qué fueron así. Además, la naturaleza del estudio es historiográfico y cultural porque se interpreta la información que se halla en fuentes, documentos o en los repositorios de las bibliotecas y demás lugares consultados. No se requiere un diseño explícito; sin embargo, se enmarca dentro de un estudio ex posfacto (después del hecho) por lo que se toma la línea longitudinal entre 1931 y 1932.

\section{Encinas y los estudios en la Universidad de San Marcos}

En 1911, el joven y normalista José Antonio Encinas ingresó a la Facultad de Letras de la Universidad de San Marcos; luego en 1913 se graduó de bachiller con la tesis titulada La educación: su función social en 
el Perú, el problema de la nacionalización, la que mereció la distinción de ser considerada en la Revista Universitaria de San Marcos para su publicación.

También había estudiado derecho en la misma Universidad. En 1918, se graduó de bachiller con la tesis Contribuciones a una legislación tutelar indígena, posteriormente se graduó de Doctor en Jurisprudencia con la sustentación, en 1919, de su valiosa tesis titulada Causas de la criminalidad indigena en el Perú, ensayo de psicología experimenal; ambas fueron publicadas por la misma Universidad.

Encinas, pedagogo e intelectual, fue producto de la sociedad de su época, preocupado por crear, renovar, replantear, contextualizar ideas pedagógicas relacionadas con los problemas generales que aquejaban a la sociedad. Sus escritos se difundieron desde algunos espacios limitados hasta cubrir amplios sectores del país. Sus ideas se difundían en conferencias, congresos, charlas y se publicaban en artículos periódisticos, revistas de investigación, libros, entre otros. Con ellos iba ampliando su llegada e influencia intelectual porque consideraba que no solo la élite oficialisla necesitaba recibir una buena educación, sino también precisaban de ella los jóvenes que no pertenecían a esa élite.

\section{Encinas y sus reflexiones para la Universidad de San Marcos}

En los años previos a su elección como rector, Encinas iba consolidando su formación porque en 1919 obtiene el grado de Doctor en Jurisprudencia en la Universidad Mayor de San Marcos. Luego en 1927 optó el grado de Master en Antropología en la Universidad de Cambridge; también estudió en las universidades de Bolonia y Padua (Italia). En 1928, ingresa a la Universidad de la Sorbona de París y optó el grado de Doctor en Educación (Casalino, 1991: 663- 664). Por lo tanto, Encinas contaba con los pergaminos, que le permitían ampliar la frontera de lo conocido y su vocación por la enseñanza.

En ese sentido, Encinas señaló que

Había vivido buena parte de mi destierro incorporado a las Universidades de Londres, Cambridge, Paris, Bolonia y Padua, en las tres primeras en condición de estudiante; por tanto, estaba enterado del proceso histórico de esas universidades, y no podía sustraerme a la obligación de apoyar el deseo de los estudiantes (Encinas 1935: 20).

En esas circunstancias, su espíritu estudiantil rebelde había estado ganando terreno con propuestas de transformación y el accionar de la universidad. En esas circunstancias se aproximaba e irrumpía el viento de la reforma universitaria de Córdoba en Argentina (1918); en aquellos años el ideal que alentaba a los estudiantes era una nueva concepción de la universidad; sin embargo, como se sabe ese fenómeno no solo ocurrió en el Perú sino en toda América Latina.

El Conversatorio Universitario que impulsó la Reforma Universitaria hacia 1919, la reactivación de (la Federación de Estudiantes del Perú) y el Congreso Nacional de Estudiantes del Cuzco que presidió Víctor Raúl Haya de la Torre, (es también) el momento del ascenso de las clases medias, la democratización de la Universidad y el inicio de la superación del racismo (Maticorena 2013: 50).

El espíritu rebelde estudiantil protagonizó la primera reforma universitaria en Lima en el siglo xx; en esos años, el sanmarquino Encinas transitaba por las aulas y era el portavoz de los estudiantes universitarios. Luego de graduarse en la misma universidad, logró las credenciales necesarias que lo respaldaban; las mismas que le permitieron brillar en discursos aleccionadores en auditorios según las circunstancias y público a quienes de dirigía.

Encinas, por esos años había sido parlamentario; es decir, fue su primer desempeño como representante por Puno durante el primer periodo del segundo gobierno de Leguía (1919-1923); sin embargo, su posterior oposición a la reelección de Leguía le valió el primero de varios destierros. Estos hechos le permitieron conocer el problema educativo en sus diferentes modalidades. Encinas no tuvo dificultad para encarar, plantear y destruir propuestas que no beneficiarían a los estudiantes, a quienes les guardaba tanta admiración por ser un maestro dedicado que se había autoidentificado con su vocación de servicio a la niñez y a la juventud en todos los espacios educativos posibles que se le presentarían.

Es así que ante el parlamento nacional defendió la idea de reorganización de San Marcos en los términos siguientes: 
Que la Universidad Mayor de San Marcos carece de una organización científica y que lo que incumbe al Parlamento no es dictar una resolución de carácter parcial, buscando fórmulas que convengan a uno y otro elemento y menos realizar reformas de índole superficial. [...] conviene que el Parlamento realice una obra efectiva, que signifique la reorganización radical de la Universidad Mayor de San Marcos. [...] delibere y estudie [...] los señores diputados Maúrtua, Tello y Martínez, actuales catedráticos de la Universidad, han hecho diversas objeciones sobre el particular; el señor Maúrtua, especialmente, ha demostrado una tendencia a colocar este problema dentro del terreno pedagógico, que es el que yo y el señor Tello nos encontramos. [...] la universidad no había preparado la eficiencia mental de sus alumnos y que la causa por la que esta eficiencia no tenía relieve era su mal sistema de enseñanza, sus métodos anticuados, su organización conservadora (Encinas: discurso 12 setiembre 1921; en Nugent 2013: 304-305).

En tal sentido, los parlamentarios Julio César Tello y José Antonio Encinas, quienes habían presentado un proyecto de ley para la reorganización de la Universidad de San Marcos y varias universidades de provincias denominadas «menores», expusieron ideas más coherentes a los tiempos exigidos para abordar tanto la enseñanza como el aprendizaje universitario de acuerdo a lo que requería la época y no como meros repetidores del texto en los exámenes, por ello, dijo:

Es interesante observar que los mejores alumnos de la Universidad, llamados así aquellos que obtienen altos calificativos en los exámenes, son los que en la mayor parte de los casos han fracasado en la vida profesional. Este hecho nos convence del error en que los profesores de la Universidad se encuentran y se encontraban de creer que el mejor alumno era aquel que podía repetir mejor un texto, o que tenía el espíritu más tranquilo a la hora del examen, o que, mediante la simpatía muy humana del jurado, podía rendir uno muy brillante. ¡Error profundo! Ese examen no tiene ningún valor. Esos alumnos, en el mejor de los casos, son simplemente virtuosos de la memoria; pero jamás demuestra aptitud para la profesión de médico, abogado o ingeniero, quienes precisamente necesitan lo contrario, esto es, observación, análisis e investigación (Encinas: discurso 12 setiembre de 1921; en Nugent 2013: 307).
Encinas era un especialista que poseía argumentos suficientes en temas de pedagogía universitaria en sus diversos componentes, que comprende el proceso de enseñar, aprender e investigar; explicaba que no todas las enseñanzas que había recibido en la Universidad le habían dotado de conocimientos adecuados, sino más bien decía que el esfuerzo personal de cada alumno era lo que le permitía consolidar una categoría profesional y no el influjo de métodos verbalistas y repetitivos de los profesores con metodologías de enseñanza tradicional. Asimismo, en otra de sus intervenciones señalaba también que

El análisis detenido de la Universidad de San Marcos nos llevaría al convencimiento de que su organización responde a un criterio medieval; eso no quiere decir que no existen varios catedráticos que merezcan el nombre de tales y a quienes es preciso que se les distinga» (Encinas: 12 setiembre 1921; en Nugent 2013: 308).

En esas líneas, rescata la labor pedagógica de algunos catedráticos de la Universidad, quienes son merecedores a un reconocimiento por su labor tan delicada como es el de formar profesionales. Ya que en el futuro serían, según nuestro maestro, los que diseñarían los rumbos de la sociedad hacia mejores destinos, gracias a su talento y los cursos recibidos en las aulas de las diversas especialidades. Además, la sociedad y las instituciones esperaban de sus graduados acciones distintas de las ya conocidas formas de enrumbar al país. Por lo que para formar estudiantes acordes con un perfil de compromiso social, se debía contar con profesores de talla académica y científica suficientes, por eso «rinde póstumo homenaje a Javier Prado, profesor de vastísima cultura, que sabía interesar a sus alumnos. Aún viven en mi espíritu las notables lecciones que, sobre Bergson, Boutrou y Rousseau escuchara en la cátedra de Filosofía Moderna» (Encinas: 12 de setiembre de 1921; en Nugent 2013: 312).

De esta forma Encinas reconocía las cualidades intelectuales de uno de sus profesores, quien le había dejado una huella académica importante; es así que Encinas asume ese reto de fidelidad a la vida académica, que a la postre se constituyó en un referente y activo debatiente intelectual, dedicando sus energías al servicio de la niñez y de la juventud desde la posición de un gestor de la educación comprometido con los ámbitos teórico y 
pragmático de la educación; rasgo que lo define desde los diversos cargos que le había tocado ejercer antes de asumir el rectorado de la Universidad de San Marcos.

Con este propósito, emprendió el proyecto de reforma universitaria, la cual quedó trunca en su fase de implementación, porque afectaba los intereses externos de la Universidad como el civilismo en alianza con unos pocos militares. La mencionada reforma no llegó a completarse, pero la siembra de sus extraordinarias ideas continuaba en los estudiantes. Al poco tiempo, por determinación del poder político, según Miguel Maticorena, el 6 de mayo de 1932, la Universidad fue recesada y el 7 de mayo de 1932 fue cerrada hasta junio de 1935. Recién el Rectorado de Luis Alberto Sánchez retornó a los postulados de la reforma universitaria en San Marcos, pero también fue apagada por el golpe militar de Odría de 1948 (Marticorena 2013: 50).

Durante su intervención en el Congreso como diputado de la Nación, Encinas, se pronuncia con respecto a la Universidad el 12 de diciembre de 1921 «la Universidad de Lima registra un alto porcentaje de triunfos alcanzados por el estudiante provinciano, a pesar del medio, que le es hostil bajo todo concepto» (Encinas: 12 setiembre 1921; en Nugent 2013: 309).

En su discurso, destaca la diversa procedencia social de los estudiantes de la universidad. Encinas salía siempre al frente a defender una educación para todos ya que así le habían dictado sus reflexiones y su cuajada probidad académica, que fue la base de su energía intelectual, la cual por un lado lo llevó hacia los debates públicos más ácidos, y por otro lado, en el ámbito de las aulas, hacia las enseñanzas más deleitantes. Encinas decía que «la labor sería más intensa si la Universidad tuviera una organización que disciplinara la mentalidad de la juventud, si sus métodos llevaran gradualmente a engendrar la capacidad de investigar antes que a una enseñanza libresca, absolutamente improductiva» (Encinas: 12 setiembre 1921; en Nugent 2013: 309).

Sin embargo, el país enfrentaba problemas presupuestales y porque los recursos económicos fueron siempre escasos y había muchas necesidades que atender, las autoridades debatían sobre cómo sufragar los gastos que demandaría el cambio que la universidad requería. Por otro lado, Encinas se formulaba interrogantes que requerían ser respondidas por los que habían gobernado el país casi por medio siglo, preguntándose en un tono cuestionador:
[...], ¿Dónde se encuentra entonces el patriotismo peruano? ¿Es posible creer que en el Perú no se encuentran fondos necesarios para coadyuvar a la enseńanza pública? ¿Dónde se encuentra ese elemento civilista poderoso, plutócrata y acaparador de bienes y rentas del país, que durante cincuenta años los ha usufructuado? [...] ¿Dónde está ese elemento que no ha contribuido siquiera con una pequeña cantidad de dinero para impulsar y estimular el espíritu de los alumnos en determinado orden de estudios? (Encinas: 12 de setiembre de 1921; en Nugent 2013: 310).

En esas líneas, Encinas, en un tono de reto a sus colegas y a la clase aristocrática y en coherencia con su discurso y su accionar aseveraba que:

En las universidades extranjeras, señores representantes, anualmente se registran cientos de becas donadas por diferentes personas, becas que varían según la cantidad y la naturaleza de ellas. ¡Yo, señores representantes, en la modesta actividad de mi vida política y en la modestísima condición de fortuna en que me encuentro, había ofrecido en mi provincia, en la última visita que hice, sostener en la Universidad Mayor de San Marcos un becario! [...], la mayor parte de estos políticos que dicen tener la hegemonía del talento, del poder y del dinero se hubieran dado cuenta del porvenir y brillantez de su apellido, de la necesidad de legar a sus hijos un timbre de honor y de orgullo, cada uno de ellos hubiera contribuido con su dinero y sus esfuerzos a la mejora de la vieja y, llamada por ellos, gloriosa universidad [...] (Encinas: 12 setiembre 1921; en Nugent 2013: 310-311).

Es así que Encinas, con su presencia en el escenario del debate, marca una época porque ponía en evidencia los problemas de la universidad en el ámbito de la enseñanza y el desempeño de los profesores en las diferentes Facultades, lo que le permitía expresarse con naturalidad porque él mismo había sido alumno y conocía desde el interior las deficiencias del proceso de enseńanza aprendizaje en la Universidad de San Marcos.

\section{José Antonio Encinas el primer rector de San Marcos elegido con participación estudiantil}

Se había lanzado la convocatoria para elegir al nuevo rector de San Marcos, la misma que se celebraría con la participación de profesores y estudiantes mediante 
sus representantes; es entonces que Encinas acepta ser candidato a Rector a insistencia del sector estudiantil que veían en él al candidato que concretizaría, una vez convertido como la máxima autoridad universitaria, las aspiraciones de juventudes reformistas que habían luchado más de una década, ya que también el mismo candidato había mostrado su adherencia para contribuir con una reforma efectiva y no solo implementar cambios epidérmicos, por decir, con características cosméticas como se preveía en el candidato contendor que postulaba por el sector conservador.

Además, el candidato Encinas percibía que la organización estudiantil tenía una importancia como tejido social universitario que podría conducir y apoyar mediante el cogobierno con la Universidad, lo cual fue bien visto por los estudiantes. La organización les permitiría ser los interlocutores válidos entre la autoridad y sus compañeros sobre el accionar de la universidad, principalmente en relación a la pedagogía universitaria. Como era natural, el candidato ofrecía poner a disposición su conocimiento sobre la universidad como consecuencia de la experiencia tenida en Europa cuando había sido estudiante; además, tenía la voluntad de renovar San Marcos, implantando cambios sustantivos, mensaje que había llegado a tener acogida abrumadoramente en el sector estudiantil.

En aquella elección de 1931 dos fueron los candidatos al rectorado de San Marcos, José Antonio Encinas, quien no había sido profesor en San Marcos y Víctor Andrés Belaunde, quien había ejercido la docencia en la universidad. Ambos habían combatido a la dictadura de Leguía y, por eso habían vivido en el destierro casi diez años; el mismo Encinas resalta a Belaunde como un profesor destacado de la Universidad que a la vez gozaba de merecido prestigio en San Marcos. Conservador en lo político y católico militante en lo religioso; sin embargo, tenía en el estudiantado ostensible resistencia. Reitero, Encinas no había sido profesor en la Universidad, pero tenía un enlace ya sea como estudiante y también como parlamentario desde donde había tenido intervención directa en los problemas relacionados a la reforma Universitaria, por ello

[...], para defender ideales de bienestar estudiantil como alumno de San Marcos, como candidato a la Presidencia de la Federación de Estudiantes, como delegado ante el Consejo Universitario y, luego, como miembro del Parlamento, Toda esta inquietud quedó disciplinada en mí larga estada en Europa; consagrado exclusivamente a estudiar problemas educativos desde el Kindergarten hasta la Universidad. Había, pues, en mí candidatura -que era la de los estudiantes- por lo menos la experiencia necesaria que garantizaba la difícil misión de interpretar los ideales de la juventud que constituyen el fundamento de cualquiera renovación social (Encinas, 1973: 63-64).

El día de las elecciones llegó sin la injerencia política del Gobierno; la fuerza estudiantil inclinó la voluntad de los profesores y se consumó la elección con una abrumadora mayoría de 84 votos para Encinas contra 14 que tuvo su contendor (Encinas, 1973: 66).

Es entonces que la llegada del año 1931 abre un nuevo capítulo en la historia de la Universidad de San Marcos, la misma cuya estructura de funcionamiento estaba constituida en Facultades con sus dependencias que habrían sido las siguientes, considerando como referente a las Facultades que integraba la universidad, comprendía²:

1. Las Facultades de Teología, Derecho, Medicina, Letras, Ciencias y Ciencias económicas.

2. Los Institutos de Farmacia y Odontología

3. Las Dependencias que establece el estatuto

Encinas, señala que en 1927 había escrito en Europa la reforma de la Universidad peruana, pero

No pensé que cuatro años después, sería llamado a ocupar el Rectorado de la Universidad Mayor de San Marcos, de Lima, elegido por la voluntad de los maestros y de los estudiantes, quienes, desde el 28 de agosto de 1930, en que terminó violentamente el gobierno de don Augusto B. Leguía, habían solicitado la reforma radical del claustro ${ }^{3}$. Sin embargo, a mi regreso de Europa, en donde pasé ocho años de destierro político, dedicado por mi cuenta a estudiar problemas educativos, los estudiantes ya en plena actividad por la reforma solicitaron mi cooperación para llevar a la práctica gran parte de sus exigencias ya admitidas y consentidas en el decreto -ley de 11 de febrero de 1931, donde habían logrado incorporar el denominado

2 Reforma de la enseñanza universitaria, Estatuto de 241 páginas declarado en vigor de acuerdo a la Ley No 6441, por el Presidente Augusto B. Leguía, 1928, p. 7.

3 José Antonio Encinas, (1935) La reforma universitaria en la universidad peruana; En Gabriel del Mazo, (1968) La reforma universitaria. Tomo III. Ensayos críticos. Imprenta UNMSM, pp.118- 119. 
cogobierno, o sea, la participación directa de los estudiantes en el gobierno y administración de la Universidad, y el derecho de tachar a profesores ${ }^{4}$.

La Ley establecía que el periodo rectoral debía ser 5 años. Es así que en el libro "Historia de las universidades de Bolonia y Padua» en un pie de página indica que el Dr. José Antonio Encinas fue elegido Rector de la Universidad Mayor de San Marcos de Lima, el 20 de marzo de 1931, por el claustro constituido por los catedráticos de la Universidad y delegados de los alumnos. Su periodo expiraba el 20 de marzo de 1936. Sin embargo, la universidad de San Marcos fue clausurada desde el 9 de mayo de 1931 (Encinas 1935: 17). Pero esta fecha de elección estaba sujeta a variación por el Consejo Universitario de la Universidad y así fue, según información que aparece en el Diario La Crónica.

Encinas era un hombre que gozaba de logros y trayectoria intelectual, producto de su esfuerzo y en reconocimiento de una justa apreciación de sus altos merecimientos académicos. Aquí es importante mencionar que, según el decreto del Gobierno del Estado, la elección estaba fijada para el 20 de marzo de 1931; sin embargo, debo resaltar que esa fecha al parecer se habría adelantado ya que el comunicado del rectorado señalaba:

El rectorado convocaba a la elección de rector por acuerdo del Consejo Universitario y en armonía con lo dispuesto por el artículo 17, incisos 1 y 4 del estatuto provisorio de 6 del mes próximo pasado convocó a los señores catedráticos y alumnos que forman parte de los consejos directivos de las Facultades y Escuelas que integran la universidad para la elección del rector de la universidad que se verificará en el local del Rectorado el sábado 14 del mes en curso de 4 a 6 pm, - la misma que fue suscrita por - el secretario de la universidad (La Crónica, 6 marzo de 1931).

Una vez realizada las elecciones, el siguiente paso inmediato fue que el flamante Rector de la Universidad Mayor de San Marcos debió haber coordinado de cómo sería la política de administración universitaria. Entonces aparecía un nuevo destino para la universidad y así comenzaría a remozarse con el vivificante y renovador impulso que le imprimió Encinas al asumir una función tan noble en esos ańos para alguien que no fue catedrático permanente de San Marcos, pero que tenía ese brillo académico y los pergaminos que lo respaldaban para ejercer el cargo de rector.

Producida la llegada de Encinas al rectorado, y en un clima concordante con la versión de Luis E. Valcárcel sobre el rectorado de Encinas declaraba que

San Marcos me ofreció esa oportunidad, pues en 1931 existía un ambiente especialmente favorable para el libre intercambio de ideas. José Antonio Encinas, su Rector, hombre joven que no llegaba a los 40 años, era un intelectual de ideas progresistas. En otros puestos de cierta responsabilidad estaban ubicados brillantes estudiosos jóvenes como Jorge Guillermo Leguía secretario general de la Universidad, Raúl Porras director del Colegio Universitario, Luis Alberto Sánchez director de departamento de Extensión Cultural y Jorge Basadre director de la Biblioteca, donde ya había iniciado el paciente trabajo de investigación que concluyó con la redacción de su monumental Historia de la República del Perú (Ríos 2009: 171-172).

Encinas ya como la primera autoridad universitaria, inició su gestión con mucha energía y vigor; además era un hombre elogiado, cuestionado; tenía seguidores y debatientes. Es así que rubricó la resolución No 23 en el que se resolvía los acuerdos del Consejo Universitario. Entre varios puntos, queremos mencionar lo referido a los acuerdos relativos a la conclusión del año universitario, la misma que decía

Lima, 26 de marzo de 1931 de conformidad con lo acordado por el Consejo Universitario, en sesión de 24 de marzo de 1931, por considerarse asunto urgente dar solución al problema planteado por la interrupción de los cursos en los últimos meses, y siendo necesario adoptar un plan que armonice la conclusión del año universitario pendiente y las exigencias del próximo se resuelve:

Durante el año en curso habrá una etapa de tres meses de estudios, durante la cual se dará término a las labores suspendidas en octubre de 1930.

Habrá también un(a) que abarcará desde el $1^{\circ}$ junio hasta el 10 de julio de presente año.

El examen será escrito u oral, a solicitud del estudiante, y el calificativo, en caso de desaprobación será motivado; 
Se organizará en cada Facultad o Instituto un tribunal de apelación, ante el cual los alumnos desaprobados en uno o más exámenes escritos pueden presentar las reclamaciones a que tuvieren derecho. Dicho tribunal estará constituido por el Decano, el catedrático del curso a que se refiere la reclamación, y un catedrático elegido por los alumnos y, en cuanto al procedimiento se someterá a la pauta que cada Facultad o Instituto fijasen.

La apertura al año universitario de 1931 se efectuará $1^{\circ}$ de agosto y tal año concluirá en febrero de 1932 inclusive.

[...] (Rector) Encinas - Jorge Guillermo Leguía (secretario) $)^{5}$.

Revisando los archivos de la Universidad de San Marcos, respecto a la actuación de las máximas autoridades, se pudo encontrar, en el caso particular, el libro de resoluciones rectorales, que nos ilustra sobre las nominaciones de los cargos a profesores, las innovaciones introducidas y otras acciones vinculantes con la universidad, lo que nos sirve de fuentes primarias para afirmar lo que se ha planteado en la investigacion.

\section{Implementación de la reforma universitaria en San Marcos 1931-1932}

A inicios de la tercera década del siglo veinte, continuaba en la universidad una atmósfera de cuestionamientos que abarcó el accionar de la Universidad de San Marcos. Sus efectos se habían ampliado cubriendo varios aspectos de la vida nacional.

En ese sentido, considero tener en cuenta lo señalado por Tomas Escajadillo quien escribió un artículo titulado «La revolución universitaria de 1930» en sus líneas menciona:

La reforma universitaria ha quedado iniciada. No pretenden los muchachos del 30 haberla ejecutado, no ignoran que es labor de varios ańos [...] allí está efectiva intervención de los alumnos en el gobierno de la Universidad. La Universidad ha dejado de ser un feudo, una pertinencia de oligarcas. Ahora es de alumnos y profesores, de cuya armoniosa y comprensiva acción, hay derecho para esperar planes de renovación (Escajadillo 1930: 107- 108).

5 Archivo: Domingo Angulo; Libro de Actas de Sesiones de Consejo Universitario Manuscrito; cuerpo 42, lado A, Nivel 2, caja № 1831, Ítem No 5167, Dependencia Consejo Universitario, serie documental Resoluciones, ańo 1931-1932, pp.8 - 9.
Como se sabe, la reforma universitaria produjo un conflicto que se ha repetido varias veces en forma ascendente en el siglo xx, empezando en 1919, luego continuó en 1930 y 1931, periodo en el que se efectivizaba el mayor conflicto social. Luego se iniciaría el camino hacia su implementación, la misma que quedó trunca. En 1945, también cobraba vigencia el conflicto de reformar la universidad. Sin embargo, ahí no finalizaría ese propósito, sino como era natural el tema de educación universitaria conllevó a mayores debates; por ello se dieron experiencias que prestaban sus oídos a los reclamos estudiantiles principalmente de reformar la universidad. Ahora bien, cuando ya se va cumplir un siglo de aquel 1919 en que empezó a circular el accionar de la reforma universitaria desde la posición estudiantil, mayormente, y luego de casi un siglo después, prácticamente la reforma contemporáneamente viene desde el Estado, impregnado de concepciones políticas y económicas que están convirtiendo en cliente al estudiante de las universidades públicas y ni qué decir de algunas instituciones universitarias privadas creadas en los últimos ańos.

Históricamente, fueron las juventudes provenientes de las universidades públicas ${ }^{6}$, quienes protagonizaban e irrumpían por incursionar en la vida política e iniciar la búsqueda de reformar las prácticas tradicionales en la universidad; pero la represión militar ahogaba sus iniciativas en las primeras protestas; aunque ańos más tarde se haría realidad con el transcurrir de los años. Es decir, hacia los años treinta del siglo pasado. Por eso, podemos señalar la presencia de los estudiantes y a la vez la predominancia de los mismos para encausarlos hacia la formación de organizaciones estudiantiles con demandas específicas como es la de recibir una sólida formación profesional.

Las demandas estudiantiles se evidenciaron, en ese entonces, con el movimiento iniciado en Córdoba, Argentina, en 1918, y en el Perú en 1919; fue un proceso sucesivo, con sentido de continuidad de buscar aires de cambio en la universidad. Fue una serie de etapas con propósitos similares, que se extendió a lo largo de América Latina, las cuales fueron madurando al pasar los años. Con tal pro-

6 Es preciso mencionar y no podemos olvidar que las primeras protestas estudiantiles se expresaron en Cusco en 1909 la misma que va anteceder a la de Lima y de Córdoba que aparecerán una década después, como resalta José Luis Rénique en 1987. 
pósito los reformistas y los que auspiciaban habían producido una diversidad y cantidad de documentos sobre temas relacionados con la educación universitaria. Así podríamos mencionar como ejemplos las publicaciones que hacían porque una forma llegar a la sociedad era mediante los medios que permitan informar qué querían los estudiantes cuando hablaban de reforma.

La Universidad Mayor de San Marcos hacia 1930-1931 presentaba ciertas peculiaridades en relación con lo que ocurría en el país. El gobierno de once años de Leguía se había desgastado tanto y era blanco de críticas desde diversos sectores. Por otro lado, la figura de Encinas como rector tenía que lidiar con problemas que tuvieron sus efectos en la Universidad, es así que ocurren acontecimientos que de hecho van a tener sus efectos para la universidad, y particularmente para los reformistas quienes guardaban sus esperanzas de que llegada la reforma se terminarían momentáneamente los problemas internos en la universidad. Sin embargo, no fue así, pues surgió un hecho con características autoritarias, que aplacó a todos sus adversarios mediante el empleo de formas violentas con tal de quedar en el gobierno nacional sin obstáculos para implementar políticas interesadas, que no siempre eran pensadas en beneficio de la mayoría de la población.

Por eso, el golpe de Estado del comandante Luis Miguel Sánchez Cerro dio inicio a la revolución de Arequipa, forzando al entonces presidente Augusto B. Leguía a dejar el cargo, y en lo sucesivo:

[...] la Revolución Universitaria, promovida por los estudiantes, quienes exigían la renovación radical de la docencia y del régimen de estudios, [...], (sin embargo) Sánchez Cerro en colaboración con el "civilismo", no puso atención a tales demandas y dejó que la rebeldía siguiera su curso hasta adquirir inusitada violencia a principios de 1931.

Sánchez Cerro, pocos días antes de su renuncia, dictó el célebre Decreto Ley de 6 de febrero de 1931 en cuyos considerandos declarábase anormal la situación de la universidad [...]. En ese mismo Decreto se reconocía [...] la representación activa del alumnado en los cuerpos directivos de la Universidad y en la elección de autoridades, así como reglamentar el ejercicio del derecho de «tacha» para renovar el cuerpo docente (Encinas, 1973: 41).
Para los estudiantes la reforma debía comprender el diseño de un nuevo proyecto de universidad, sustentado en la expresión democrática, con puertas abiertas a una participación amplia para que estudien los hijos del pueblo y no solo de ciertos pequeños círculos. Por lo que los estudiantes habían conseguido tres propósitos fundamentales que son parte de la reforma las cuales fueron:

Participar en el Gobierno de la Universidad, intervenir en la selección de los profesores y elegir al Rector por procedimiento indirecto, [...] Dicho decreto - Ley entró en vigor cuando Sánchez Cerro abandonó el Poder y lo reemplazó don David Samanéz Ocampo bajo cuyo gobierno se eligió al Rector [...] (Encinas 1973; 42).

En aquella disposición legal estaban contempladas buena parte de las peticiones estudiantiles que desde años atrás habían reclamado, pero lo que no habían percibido los estudiantes en sus reclamos, en primer lugar, era el componente referido al estudiante de condiciones de vida adecuadas ya sea en el aspecto físico, mental y espiritual, y en segundo lugar, a recibir una educación que satisfaga sus necesidades e intereses sobre la base de una formación sólida.

\section{Encinas y su legado como rector de San Marcos}

Encinas en su recorrido de vida académica e intelectual dejó importantes huellas. Por eso, como educador paradigmático y en reconocimiento a su trayectoria se debe recordar y alimentar a las generaciones con sus ideas, considerándolas en el calendario escolar en fechas cívicas mediante procedimientos de diversa índole como la lectura de sus obras.

Además de la exposición de su producción bibliografíca, también podría recurrirse a la representación artística ya sea en forma de pinturas, fotografías, mausoleos o establecimiento de un museo pedagógico con todo lo producido e interactuado por el maestro que fortalecería la educación desde la perspectiva de pensadores peruanos de la educación, que concibieron las ideas más elaboradas para la época.

Porque Encinas buscaba que los estudiantes desarrollen todas sus potencialidades y así formarse con sólidas bases académicas, ya que para llegar a la meta 
se tenía que atravesar por las dificultades que aparecerían durante la implementación de la reforma. Por eso se había iniciado la batalla para democratizar la educación universitaria. Con este fin hizo un llamado para que se comprometieran a los integrantes de la comunidad universitaria en esa lucha que fue dura y tomaría ańos, sustuvo.

El camino el intento de reforma se consumió en generaciones de profesores y alumnos, porque la verdadera reforma universitaria no ha de venir a partir de una ley, sino que es asunto de la universidad; concretizarla para que realmente los beneficiados sean los estudiantes. Ya que para ellos se había creado a partir de su rectorado un nuevo orden pedagógico, pues atrás habían quedado las prácticas de ciertos profesores sin vigencia ni en el mundo ni en el Perú porque sus clases rutinarias los habían conducido por ese camino caduco y final.

Encinas buscó diseñar y concretar su programa, poniendo a la universidad al servicio y transformación del país. A la fecha, desde 1931, han transcurrido 88 años desde aquella fecha en que los estudiantes eligieron a Encinas como Rector; es decir, aquella avalancha estudiantil, desde sus bases, logró sentar en el rectorado a un intelectual que convencía con sus reflexiones a cuantos aparecían en su delante. Era un hombre de edad mediana con las credenciales necesarias intelectualmente, que contribuyó a dar vida a la reforma universitaria, logrando apagar la ira estudiantil.

Si bien Encinas destruyó la obsolescencia de la organización académica, construyó un nuevo proyecto que interpretaba las necesidades y aspiraciones de la juventud y de la sociedad en general; así la universidad tomó el rumbo distinto a lo tradicional. Empero debo seńalar que toda iniciativa de reforma no fue bien vista por cierto sector de universitarios como promisoria. A la vez sus detractores a la posteridad mostraron las debilidades propias surgidas en toda institución que comienza su reforma. Sin embargo, sobre la marcha, era posible mejorarla, ya que los intereses superiores de la universidad entre otros fueron el Colegio Universitario y la Escuela de Altos Estudios, además de otras que fueron llevadas a San Marcos por Encinas, cuando la vida le dio la oportunidad de ser su máxima autoridad.

En esa línea puedo afirmar y mostrar que, a inicios de 1931, el futuro de la universidad se había vislumbrado con características particulares porque el ambiente de estabilidad institucional presentaba resquebrajamientos, ya que la resolución N. ${ }^{\circ} 1$ de 3 de enero de 1931 fue firmada por el rector José Matías Manzanilla. Todo aquello fue aprobado en sesión de Consejo Universitario desarrollado el 30 de diciembre de 1930 .

El 9 de febrero de 1931, la resolución N.o 7 fue firmada por última vez por el rector, porque en el documento se resolvía: licencia para el señor rector José Matías Manzanilla, rector de la Universidad Nacional Mayor de San Marcos por 30 días con goce de sueldo ${ }^{7}$.

Seguidamente, a partir del libro de resoluciones manuscritas, se constata que había asumido el rectorado interinamente el catedrático W.F. Molina, quien firma las resoluciones rectorales desde el N. ${ }^{\circ} 8$ hasta el N. ${ }^{\circ}$ 12, estos cinco documentos fueron emitidos en el mes de marzo del mismo ańo; desde la resolución N.o 13 hasta la N. ${ }^{o} 18$ fueron firmadas por otro encargado del rectorado. Me refiero al catedrático C.V. Lisson, cuya última resolución de encargatura tiene la fecha de 18 de marzo. En consecuencia desde enero y marzo, la universidad tuvo tres rectores sin contar todavía a Encinas como rector.

Con el propósito de contribuir al conocimiento de los hechos en la universidad y aportar datos en base a fuentes primarias, ya que en los ensayos escritos que existen sobre el personaje, motivo de este estudio, se encuentran informaciones incorrectas y otras veces no precisas; por ello, sostengo que el documento de la Universidad señalaba como fecha de elección el 20 de marzo de 1931, pero

el rectorado había convocado por acuerdo del consejo universitario y en armonía con lo dispuesto por el artículo 17, incisos 1 y 4 del estatuto de 6 del mes próximo pasado, en merced a ello, lanzó una convocatoria el rectorado y la secretaria general de la universidad, a los señores catedráticos y alumnos que forman parte de los consejos directivos de las facultades y escuelas que integran la universidad para la elección del rector de la universidad que se verificará en el local del rectorado el sábado 14 del mes en curso de 4 a $6 \mathrm{pm}^{8}$.

\footnotetext{
7 Archivo Histórico: Domingo Angulo; Libro de actas de Sesiones de Consejo Universitario manuscrito; cuerpo 42, lado A, Nivel 2, caja no 1831 , ítem no 5167. Dependencia Consejo Universitario, serie documental Resoluciones, año 1931-1932. p.2. UNMSM.

8 Diario, La Crónica 13 de marzo, 1931. Año I, no 4 p. 6.
} 
Luego de desarrollarse la elección, al día siguiente, el 15 de marzo se publican en varios medios escritos el triunfo del Dr. Encinas en la elección para el rectorado de la Universidad de San Marcos.

Una vez asumido el cargo, la primera actuación de Encinas, como autoridad, fue la emisión de la resolución N. ${ }^{\circ} 19$ de 24 de marzo de 1931, y precisamente en dicho documento se señala que de conformidad con lo resuelto por el consejo universitario de la fecha se nombre Secretario General de la Universidad al señor Jorge Guillermo Leguía, en la que firmaba Encinas como Rector de la Universidad Nacional Mayor de San Marcos, la misma que es la primera resolución en la que estampó su firma para la universidad, sin embargo, es la continuación del año $1931^{9}$.

En definitiva, podemos advertir que desde la resolución N. ${ }^{o} 19$ hasta la resolución rectoral N. 399 , emitida el 24 de diciembre de 1931, esta fue la última del año firmada por José Antonio Encinas como autoridad universitaria, quien emitió un total de 380 resoluciones, con los que demostró su gestión sin cumplir todavía un año de su mandato. $\mathrm{Al}$ año siguiente, suscribió la resolución N. ${ }^{\circ} 1$ el 7 de enero hasta la N.o 83 el 20 de abril de 1932. Al parecer es la última resolución que firma como rector Encinas ${ }^{10}$, según consta en el libro de manuscritos de resoluciones, las mismas que se encuentran resguardadas en los ambientes del Archivo Histórico Domingo Angulo de la Universidad Mayor de San Marcos.

Por tanto, en relación a la reforma universitaria, que Encinas encabezó en 1931 en su condición de Rector de la Universidad Mayor de San Marcos, introdujo innovaciones que benefeciaban mayormente a los estudiantes, tales como la implementación del cogobierno universitario y el inicio de una nueva organización académica de instituciones, entre las que se pueden mencionar al Instituto Preparatorio, el Colegio Universitario y la Escuela de Altos Estudios. La nueva política de dirección universitaria y así mismo el asumir el máximo cargo universitario avi-

9 Archivo Histórico: Domingo Angulo; Libro de actas de Sesiones de Consejo Universitario manuscrito; cuerpo 42, lado A, Nivel 2, caja No1831, Ítem No 5167, Dependencia Consejo Universitario, serie documental Resoluciones, año 1931-1932, p. 7. UNMSM.

10 Archivo: Domingo Angulo; Libro de Actas de Sesiones de Consejo Universitario manuscrito; cuerpo 42, lado A, Nivel 2, caja No 1831, Ítem No 5167, Dependencia Consejo Universitario, serie documental Resolución, año 1931-1932. UNMSM. zoraban un mejor futuro para la Universidad, que finalmente abriría sus puertas a todos los sectores de la población, que antes no habían accedido a la educación superior, con lo que su apuesta por la educación a amplios sectores se convertía en realidad. Por ello, sin lugar a dudas, fueron importantes los aportes de Encinas para la Universidad peruana.

\section{Conclusiones}

José Antonio Encinas, rector de la Universidad Nacional Mayor de San Marcos, fue elegido por profesores y estudiantes a mediados de marzo de 1931 para un periodo de cinco años. Cuando asumió el cargo, lideró la implementación académica e innovadora en concordancia con las ideas de la reforma universitaria, que buscaba la modernización; entre los principales cambios que se dieron fueron el inicio del cogobierno, la introducción de una nueva organización académica como la Sección Preparatoria, el Colegio Universitario y la Escuela de Altos Estudios, las mismas que fueron implementadas con los aprendizajes logrados en las universidades europeas de Bolonia y Padua, pues en esas aulas había profundizado sus conocimientos, alternando con grandes pensadores y templado su carácter en importantes debates. Con todo ello derribó la práctica universitaria tradicional y conservadora en San Marcos.

El rector Encinas inició una política de publicaciones como el Boletín Universitario a partir de marzo de 1931, periodo en que se editaron 16 números hasta febrero de 1932. También se publicaron documentos que reseñaban las principales actividades académicas, ceremonias, resoluciones rectorales y otros documentos importantes. Asimismo, se difundía la vida cultural de docentes, estudiantes y administrativos, integrantes de la universidad

José Antonio Encinas, rector de la Universidad Nacional Mayor de San Marcos, suscribió 380 resoluciones rectorales desde el 24 de marzo hasta diciembre de 1931, y 83 resoluciones rectorales hasta el 20 de abril de 1932. Resoluciones, que están resguardados en el archivo Domingo Angulo, con lo que se demuestra que era un rector reformador de la universidad en la que plasmó su capacidad pedagógica e intelectual de gran contenido social y democrático.

\section{Fuentes y referencias}




\section{Fuentes primarias}

Periódicos y Revistas

El Socialista. 1932. Lima

La Crónica. Lima. Marzo 1931

Variedades, Año XXVII, 28 enero de 1931, № 1195

Documentos

Boletín Universitario Órgano de la Universidad Mayor de San Marcos.

Año I - No 1 de 28 de 1930. Lima.

Año I - No 2 al No 14 de 1931. Lima.

Año I - No 15 al No 16 de 1932. Lima

Archivo Histórico: Domingo Angulo; Libro de actas de Sesiones de Consejo Universitario manuscrito; cuerpo 42, lado A, Nivel 2, caja no 1831, ítem no 5167. Dependencia Consejo Universitario, serie documental: Resoluciones, año 1931-1932. UNMSM.

\section{Referencias}

Basadre, J. (2005[1939]). Historia de la República del Perú 1822-1933. T. 12. Lima: El Comercio S.A.

Воввіо, N. (1998). La duda y la elección. Intelectuales y poder en la sociedad contemporánea. Barcelona: Ediciones Paidos Ibérica S.A.

Burga, M. (2008). La reforma silenciosa. Descentralización, desarrollo y universidad regional. Lima: Fondo Editorial PUCP, Universidad de Pacífico, IEP.

Casalino, C. (1991). (Compilación, introducción y notas) Diseñando el Perú. José Antonio Encinas Alberto Ulloa Sotomayor pensamiento politico 1945-47. Lima: Centro de investigación legislativa Senado de la República.

CHARTIER, R. (2005). El mundo como representación. Estudios sobre historia cultural. Barcelona: Gedisa Editorial S. A.

Encinas, J. (1913). La educación: su función social en el Perú en el problema de la nacionalización. Tesis para optar el grado de bachiller. Universidad Nacional Mayor de San Marcos. Facultad de Filosofía y Letras. Lima: Imprenta Peruana. E.Z. Casanova.

Encinas, J. (1935). Historia de las universidades de Bolonia y Padua. Santiago de Chile: Ediciones Ercilla.

Encinas, J. (1973). La reforma universitaria en el Perú 1930-1931. Lima: Ediciones 881.
Eguiguren, L. (2009). En: Ríos Burga, J. La universidad en el Perú: historia presente y futuro. Volumen IV La Universidad en la primera mitad del siglo XX, Lima: Edición de ANR.

Escajadillo, T. (1930). La revolución universitaria de 1930, Lima.

Giesecke, M. (2015). Política educativa y ruralidad en el Perú: 1900 a 1930. 2 tomos. Tesis presentada a la Universidad Nacional Mayor de San Marcos. Facultad de Ciencias Sociales, para optar el grado académico de doctora en Ciencias Sociales. Lima. En: http://cybertesis.unmsm.edu.pe/.

Lecaros, F. (Selección documental) (2001). Emilio Romero Parlamentario, tomo I. Lima: Fondo editorial del Congreso del Perú.

Mariátegui, S. (1994). 100 años Mariátegui Total Tomo I, Lima: Empresa Editora Amauta S.A. (Ordenamiento de textos y dirección de edición).

Maticorena M. (2013). La Universidad de San Marcos de Lima. Documentación Histórica. Lima: Fondo Editorial UNMSM y Vicerrectorado Académico.

Nugent, G. (2013). José Antonio Encinas. Por la libertad de pensamiento. Discursosparlamentarios. Tomo I (Selección). Lima: Fondo editorial del Congreso del Perú.

Reforma de la enseñanza universitaria (1928). Estatuto declarado en vigor de acuerdo con la Ley No 6041. Talleres tipográficos de la prensa Lima.

Ríos, J. (2009). La universidad en el Perú: historia presente y futuro. Volumen IV. «La Universidad en la primera mitad del siglo XX». Lima: Edición de la ANR.

SÁNCHEZ, L. (1985). La universidad no es una isla: un prólogo, un estudio, un plan, tres discursos. Lima: Editorial Okura.

SÁnchez, L. (1987). Testimonio personal: memorias de un peruano del siglo XX. Lima: Editorial Mosca Azul, 6 Volúmenes.

Velázquez, M. (2008). Porras y San Marcos (407-413) En: Libro de Homenaje a Raúl Porras Barrenechea Testimonios. Lima: UNMSM, Instituto Raúl Porras Barrenechea, Centro de Altos Estudios y de Investigaciones Peruanas. 